\title{
Combined Hepatocellular Carcinoma and Neuroendocrine Carcinoma with Ectopic Secretion of Parathyroid Hormone: A Case Report and Review of the Literature
}

Hyun Jung Kwon · Ji-Won Kim ${ }^{1}$ Haeryoung $\mathrm{Kim}^{2}$ · YoungRok Choi ${ }^{3}$ Soomin Ahn

Department of Pathology and 'Division of Hematology and Medical Oncology, Department of Internal Medicine, Seoul National University Bundang Hospital, Seongnam; '2Department of Pathology, Seoul National University Hospital, Seoul; 'Department of Surgery, Seoul National University Bundang Hospital, Seongnam, Korea

Received: April 16, 2018

Accepted: May 15, 2018

\section{Corresponding Author}

Soomin Ahn, MD

Department of Pathology, Seoul National University

Bundang Hospital, 82 Gumi-ro 173beon-gil,

Bundang-gu, Seongnam 13620, Korea

Tel: $+82-31-787-3379$

Fax: +82-31-787-4012

E-mail: suminy317@gmail.com
Primary combined hepatocellular carcinoma ( $\mathrm{HCC}$ ) and neuroendocrine carcinoma is a rare entity, and so is hypercalcemia due to ectopic parathyroid hormone (PTH) secretion by tumor. A 44-year old man with hepatitis $B$ virus associated chronic liver disease presented with a hepatic mass. Hemihepatectomy discovered the mass as combined HCC and poorly differentiated cholangiocarcinoma. During adjuvant chemoradiation therapy, he presented with nausea, and multiple systemic metastases were found. Laboratory tests revealed hypercalcemia with markedly elevated PTH and neuron specific enolase. Parathyroid scan showed normal uptake in parathyroid glands, suggestive of ectopic PTH secretion. Subsequently, immunohistochemistry of neuroendocrine marker was performed on the primary lesion, and confirmed the neuroendocrine differentiation in non-HCC component. The patient died 71 days after surgery. This report may suggest the possibility of ectopic PTH secretion by neuroendocrine carcinoma of hepatic origin causing hypercalcemia. Caution for neuroendocrine differentiation should be exercised when diagnosing poorly differentiated HCC.

Key Words: Combined; Liver; Carcinoma, hepatocellular; Carcinoma, neuroendocrine
Primary neuroendocrine carcinoma (NEC) in the liver is a rare entity that behaves aggressively. Primary hepatocellular carcinoma (HCC) with a NEC component is very rare, consisting of about $0.46 \%$ of primary hepatic tumors. ${ }^{1}$ Eighteen cases of primary combined or collided NEC and HCC have been reported in English literature to this date. ${ }^{1-14}$ None of these cases had paraneoplastic syndromes or proved to be functional.

Hypercalcemia is a well-known paraneoplastic metabolic condition associated with many malignancies. ${ }^{15}$ In HCC, hypercalcemia accounts for $7.8 \%$ of the paraneoplastic syndromes. ${ }^{16}$ While primary hyperparathyroidism is the most common cause for hypercalcemia without malignancies, hypercalcemia can occur in association with malignancies through other mechanisms. Most of the malignancies associated with hypercalcemia proved to be caused by parathyroid hormone (PTH)-related peptide (PTHrP). ${ }^{17}$ Metastasis of the malignancies to the bone can also cause osteolysis leading to hypercalcemia. ${ }^{17}$ Only rare cases are considered to be a result of ectopic PTH production by the tumors.

Here, we present a rare case of combined hepatic NEC and HCC with malignancy associated hypercalcemia caused by ectopic PTH production. Previously reported primary mixed HCC and NEC cases and ectopic PTH-producing HCC cases are also summarized and discussed.

\section{CASE REPORT}

A 44-year-old man presented with a hepatic mass discovered during a regular abdominal ultrasound for hepatitis B virus associated chronic liver disease. The chronic liver disease was diagnosed 9 years ago and the patient was on Tenofovir. Laboratory findings showed elevated white blood cells $(17,000 / \mu \mathrm{L})$, mildly elevated aspartate aminotransferase ( 4 IU/L), alanine transaminase (22 IU/L), and normal calcium and phosphate levels. Computed tomographic scan identified one huge mass in segment 
(S) 8 and the other small mass in S6, with thrombi in right portal and hepatic veins. No other systemic lesion was found. The patient underwent right hemihepatectomy with partial diaphragm resection and lymph node dissection.

On pathological examination, the cut section of $S 8$ revealed a yellow-whitish mass measuring $10.5 \times 8.0$ with irregular margins and necrosis. The mass in $\mathrm{S} 6$ was a yellowish multinodular mass that measured $1.3 \times 1.0$. Tumor thrombosis was noted in the right portal vein, and cirrhosis was observed in the nonneoplastic liver. Histologically, the main mass in S8 consisted of two components; a dominant poorly differentiated carcinoma component (60\%) composed of small tumor cells with enlarged vesicular irregular nuclei, high nuclear to cytoplasmic ratio, large nucleoli, and frequent mitoses, and multiple foci of typical HCC component (40\%) showing trabecular architecture and grade 2 nuclei (Fig. 1). The tumor penetrated the Glisson's capsule directly invading the diaphragm and showed extensive necrosis and microvessel invasion. The poorly differentiated carcinoma component was focally positive for cytokeratin (CK) 7 and negative for $\alpha$-fetoprotein, hepatocyte, glypican-3, and CK19 immunohistochemistry, and was interpreted as poorly differentiated cholangiocarcinoma component. The pathologic diagnosis of S8 mass was combined HCC and cholangiocarcinoma. The other mass in S6 showed typical histologic features of HCC. There was no metastasis in 22 lymph nodes.

The patient subsequently received adjuvant concurrent chemoradiation therapy (CCRT) of one cycle of 5 -flourouracil chemotherapy and two cycles of $5 \mathrm{fx}$ radiation. On postoperative day 59, he visited the emergency room for nausea and vomiting. Laboratory results showed elevated levels of total calcium (13.2 $\mathrm{mg} / \mathrm{dL}$; normal range, 8.8 to 10.5$)$, ionized calcium $(2.3 \mathrm{mmol} /$ $\mathrm{L}$; normal range, 1.05 to 1.35$)$, blood urea nitrogen $(33 \mathrm{mg} / \mathrm{dL}$; normal range, 10 to 26$)$, and creatinine $(2.16 \mathrm{mg} / \mathrm{dL}$; normal range, 0.7 to 1.4 ) with normal to low levels of phosphate. Further evaluation of hypercalcemia revealed markedly increased PTH

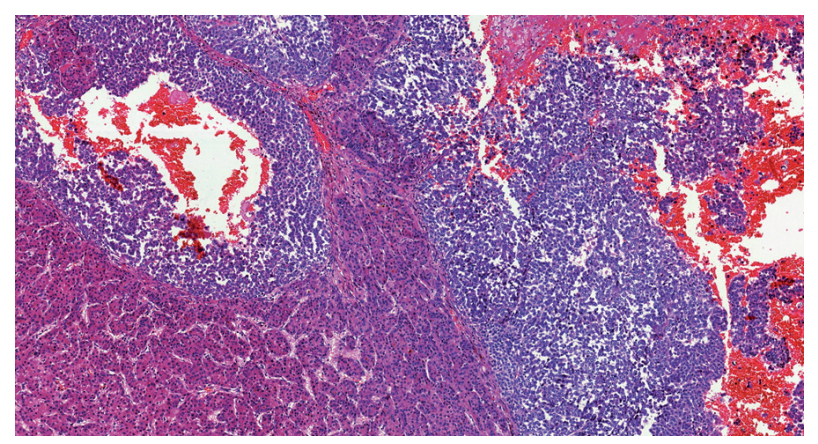

Fig. 1. Representative histologic image of the main hepatic mass.
(3,859 by enzyme-linked immunosorbent assay; normal range, 15 to 65$)$, and neuron-specific enolase (101.04 ng/mL; normal range, 0 to 16.3). Parathyroid scan was performed to exclude primary hyperparathyroidism, which showed no abnormality. Whole body positron emission tomography revealed multiple hypermetabolic lesions in the liver and whole skeleton, and biopsy of an osteolytic lesion involving a left rib discovered metastatic poorly differentiated carcinoma. Only the poorly differentiated carcinoma component, not the HCC component, was identified in the metastatic lesion. Regarding hypercalcemia, elevated PTH could not be explained with bone metastasis or PTHrP, and hypercalcemia persisted despite management. Finally, ectopic PTH production by the tumor was suggested as the cause of hypercalcemia.

Meanwhile, the clinician in charge enquired to the pathologist of the presence of NEC component in the tumor based on the possibility that ectopic hormone could be secreted by NEC, the rapid progression of the tumor and the elevated neuron-specific enolase level. Subsequent immunohistochemistry of neuroendocrine markers and PTH were performed on both primary (S8 mass) and metastatic tumor specimens. CD56 stained positive while chromogranin and synaptophysin were focally positive in the poorly differentiated area on both specimens, implying neuroendocrine differentiation (Fig. 2). The component with typical HCC morphology was negative for all three markers (Fig. 2). There was no immunoreactivity for PTH on either specimen. Symptomatic treatment including continuous renal replacement therapy was applied for the acute renal failure induced by hypercalcemia. However, the patient expired of disease progression 2 months after diagnosis.

This study was approved by the Institutional Review Board of Seoul National University Bundang Hospital (IRB No. B-1801442-702), and patient consent was waived.

\section{DISCUSSION}

Primary combined HCC and NEC is very rare. The initial pathologic diagnosis of this case was combined HCC and cholangiocarcinoma because its poorly differentiated component bore little resemblance to typical NEC morphology. However, with clinical suspicion, immunohistochemistry revealed multifocal areas within the poorly differentiated component that stained positive for neuroendocrine markers. Therefore, we classified it as combined HCC and NEC.

The clinical characteristics of the 18 reported cases of primary mixed HCC and NEC are summarized in Table 1. Most cases 

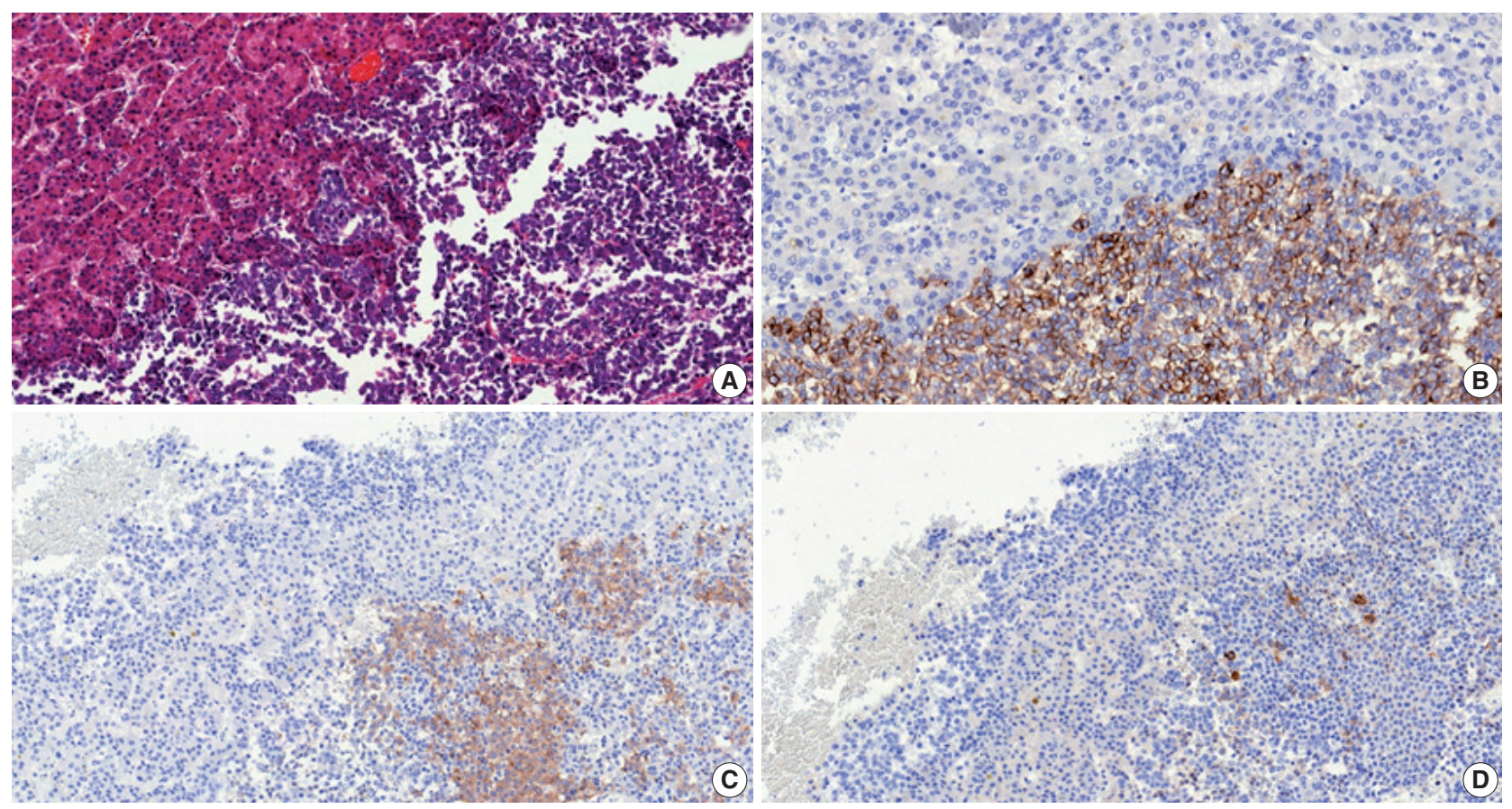

Fig. 2. (A) The main hepatic tumor consists of neuroendocrine carcinoma (right side) and hepatocellular carcinoma (left side) components. On immunohistochemistry, the neuroendocrine carcinoma component is focally positive for CD56 (B), chromogranin (C), and synaptophysin (D).

were associated with chronic hepatitis $\mathrm{B}$ or $\mathrm{C}$. The reported carcinomas have been classified to two types according to its spatial histologic arrangement. Combined types have a transition zone in which HCC and NEC intermingle with each other whereas collision types show clear separation of the histologically different components, usually by fibrous septa. In our case, the HCC was tightly intermingled with the NEC component, their borders almost indiscernible due to transition zones. Therefore, we classified it as combined HCC and NEC.

Primary mixed HCC and NEC generally tend to have a poorer prognosis than conventional HCC. ${ }^{1}$ Of the 18 cases summarized, eight patients experienced recurrence, six patients died within the year of operation from the disease, and only two patients were confirmed to be alive 2 years after surgery (Table 1). Remarkably, in the cases with biopsy-confirmed metastasis, the NEC component was solely found in all occasions, similar to the presenting case. This indicates that the NEC component acts more aggressively, which has a much poorer prognosis than primary HCC. ${ }^{1}$ Therefore, it is important to identify the neuroendocrine component and assure proper treatment be given to the patient.

None of the reported combined HCC-NEC described paraneoplastic syndrome or ectopic hormone production. To our knowledge, our case may be the first to report primary mixed HCC and NEC associated with malignancy-related hypercalcemia caused by ectopic PTH production. The patient had multiple bone metastases, and one of which was histologically confirmed. In hypercalcemia caused by osteolytic lesions or PTHrP produced by tumors, however, PTH levels are usually suppressed. ${ }^{15}$ It led us to favor ectopic PTH production to be the cause for hypercalcemia than bone metastasis or PTHrP, even though serum PTHrP level was not available.

The prevalence of hypercalcemia accounts for $7.8 \%$ of the paraneoplastic syndromes observed in HCC, and is associated with short survival. ${ }^{16}$ Ectopic PTH production has been reported in only three HCC cases (Table 2) and not in any primary hepatic NEC case. All three cases performed PTH immunohistochemistry on their biopsy specimens which were negative. Our case also showed negative results. These findings, rather than acting as counter-evidence of hormone production, may suggest that the tumor cells do not store PTH but secrete it into circulation soon after synthesis. ${ }^{18,19}$ We were not able to perform genetic analysis or RNA sequencing for PTH mRNA. As hypercalcemia developed during adjuvant CCRT, comparison of intact PTH levels of before and after the operation or CCRT was impossible. However, in our case, the patient developed hypercalcemia with elevated intact PTH as the metastatic lesions formed. Considering that the metastatic component was NEC, it may be possible to suggest that the intact PTH was synthesized by the NEC cells.

Primary hepatic NEC has poor prognosis, and the NEC component of primary mixed HCC and NEC behaves aggressively. 


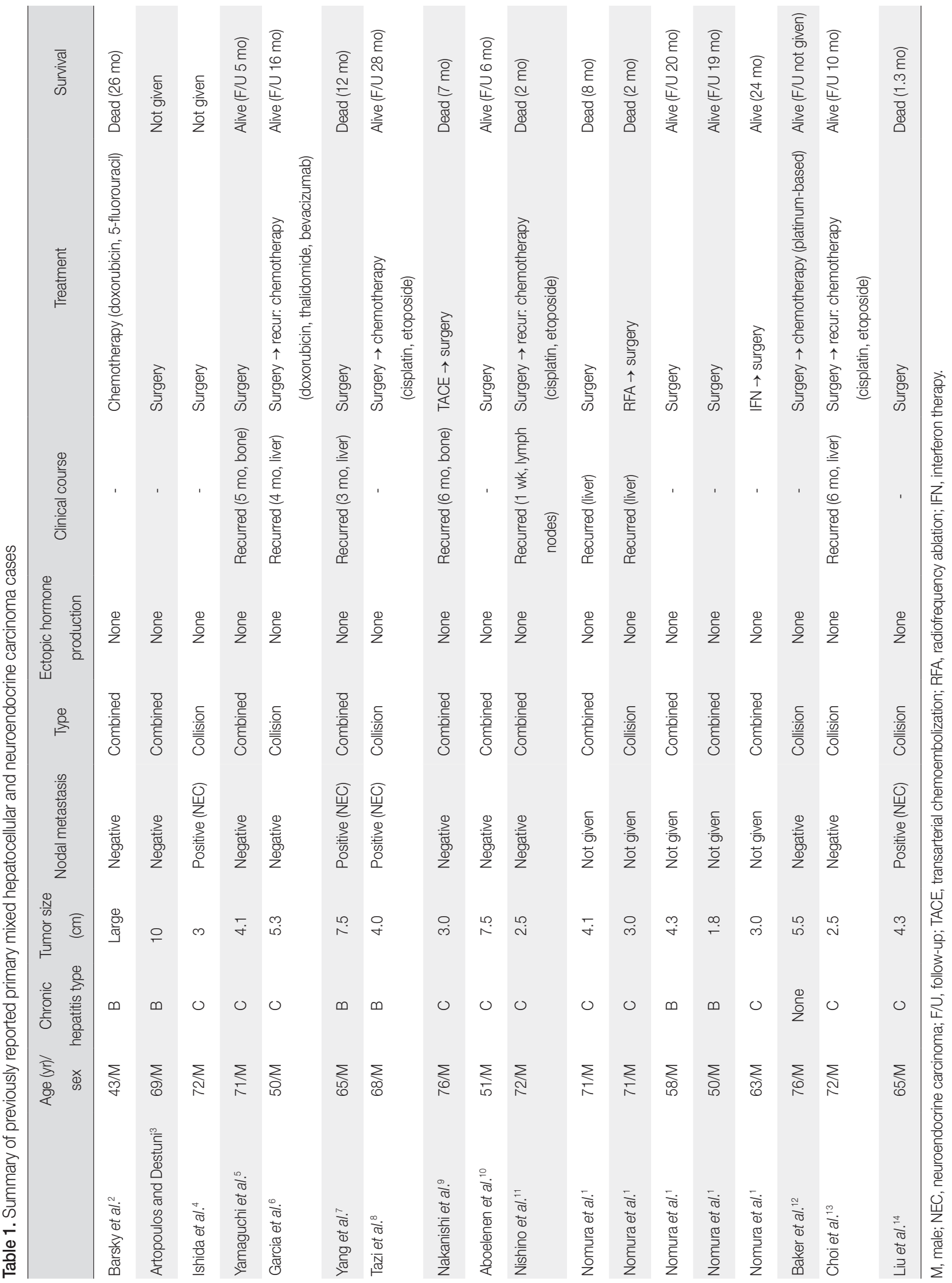


Table 2. Summary of previously reported hepatocellular carcinoma cases with ectopic PTH production

\begin{tabular}{|c|c|c|c|c|c|c|c|c|c|c|c|}
\hline & \multirow[b]{2}{*}{$\begin{array}{l}\text { Age/ } \\
\text { Sex }\end{array}$} & \multirow{2}{*}{$\begin{array}{c}\text { Chronic } \\
\text { hepatitis } \\
\text { type }\end{array}$} & \multirow{2}{*}{$\begin{array}{l}\text { Hepatocellular } \\
\text { carcinoma }\end{array}$} & \multicolumn{4}{|c|}{ Initial laboratory findings } & \multirow[b]{2}{*}{$\begin{array}{l}\text { - Parathyroid } \\
\text { lesion }\end{array}$} & \multirow[b]{2}{*}{ Treatment } & \multirow[b]{2}{*}{$\begin{array}{l}\text { Method of ectopic } \\
\text { PTH confirmation }\end{array}$} & \multirow[b]{2}{*}{ Survival } \\
\hline & & & & $\begin{array}{l}\text { Calcium } \\
\text { (mg/dL) }\end{array}$ & $\begin{array}{c}\text { Intact PTH } \\
(\mathrm{pg} / \mathrm{mL})\end{array}$ & $\begin{array}{c}\text { PTHrP } \\
\text { (pmol/L) }\end{array}$ & $\begin{array}{c}\mathrm{AFP} \\
(\mathrm{ng} / \mathrm{mL})\end{array}$ & & & & \\
\hline $\begin{array}{l}\text { Koyama } \\
\text { et al. }{ }^{20}\end{array}$ & $83 / \mathrm{M}$ & $\mathrm{C}$ & $\begin{array}{l}\text { Single } 8 \mathrm{~cm} \\
\text { mass }\end{array}$ & $\begin{array}{l}13.0 \\
(8.9-10.1)\end{array}$ & $\begin{array}{l}360 \\
\quad(15-50)\end{array}$ & $\begin{array}{l}18.7 \\
(13.8-55.3)\end{array}$ & $\begin{array}{r}29.348 \\
(0-10)\end{array}$ & None & TAE & $\begin{array}{l}\text { Venous sampling } \\
\text { Decreased serum } \\
\text { calcium and } \\
\text { intact PTH after } \\
\text { TAE }\end{array}$ & $\begin{array}{c}\text { Alive (F/U } \\
24 \mathrm{mo})\end{array}$ \\
\hline $\begin{array}{l}\text { Mahoney } \\
\text { et al. } .^{19}\end{array}$ & $72 / \mathrm{M}$ & None & $\begin{array}{l}\text { Multiple large } \\
\text { lesions, } \\
\text { extending into } \\
\text { portal vein }\end{array}$ & $\begin{array}{l}14.5 \\
(8.5-10.5)\end{array}$ & $\begin{array}{l}92 \\
(12-65)\end{array}$ & $<0.7(<1.3)$ & Not given & $\begin{array}{r}\text { Parathyroid } \\
\text { adenoma }\end{array}$ & $\begin{array}{c}\text { Parathyroid } \\
\text { resection } \\
\text { and TACE }\end{array}$ & $\begin{array}{l}\text { Sestamibi SPECT } \\
\text { scan } \\
\text { Immunoradiometric } \\
\text { assay and rapid } \\
\text { assay }\end{array}$ & $\begin{array}{l}\text { Dead (not } \\
\text { given) }\end{array}$ \\
\hline $\begin{array}{l}\text { Abe } \\
\text { et al. }{ }^{18}\end{array}$ & $73 / F$ & B & $\begin{array}{l}\text { Large mass } \\
\text { with multiple } \\
\text { metastasis }\end{array}$ & $\begin{array}{l}12.9 \\
(8.5-10.5)\end{array}$ & $99(<60)$ & $<1$ (not given) & $\begin{array}{l}189.3 \text { (not } \\
\text { given) }\end{array}$ & None & TACE & $\begin{array}{l}\text { Decreased serum } \\
\text { calcium and intact } \\
\text { PTH after TACE }\end{array}$ & $\begin{array}{l}\text { Dead } \\
(2 \mathrm{mo})\end{array}$ \\
\hline
\end{tabular}

PTH, parathyroid hormone; PTHrP, PTH-related peptide; AFP, $\alpha$-fetoprotein; M, male; TAE, transcatheter arterial embolization; F/U, follow-up; TACE, transarterial chemoembolization; SPECT, single-photon emission computed tomographic.

Clinicians and pathologists are advised to take caution for neuroendocrine differentiation when diagnosing poorly differentiated HCC.

\section{Conflicts of Interest}

No potential conflict of interest relevant to this article was reported.

\section{REFERENCES}

1. Nomura Y, Nakashima O, Akiba J, et al. Clinicopathological features of neoplasms with neuroendocrine differentiation occurring in the liver. J Clin Pathol 2017; 70: 563-70.

2. Barsky SH, Linnoila I, Triche TJ, Costa J. Hepatocellular carcinoma with carcinoid features. Hum Pathol 1984; 15: 892-4.

3. Artopoulos JG, Destuni C. Primary mixed hepatocellular carcinoma with carcinoid characteristics: a case report. Hepatogastroenterology 1994; 41: 442-4.

4. Ishida M, Seki K, Tatsuzawa A, et al. Primary hepatic neuroendocrine carcinoma coexisting with hepatocellular carcinoma in hepatitis C liver cirrhosis: report of a case. Surg Today 2003; 33: 214-8.

5. Yamaguchi R, Nakashima O, Ogata T, Hanada K, Kumabe T, Kojiro M. Hepatocellular carcinoma with an unusual neuroendocrine component. Pathol Int 2004; 54: 861-5.

6. Garcia MT, Bejarano PA, Yssa M, Buitrago E, Livingstone A. Tumor of the liver (hepatocellular and high grade neuroendocrine carcinoma): a case report and review of the literature. Virchows Arch 2006; 449: 376-81.

7. Yang CS, Wen MC, Jan YJ, Wang J, Wu CC. Combined primary neuroendocrine carcinoma and hepatocellular carcinoma of the liver. J Chin Med Assoc 2009; 72: 430-3.

8. Tazi EM, Essadi I, M'Rabti H, Errihani H. Hepatocellular carcinoma and high grade neuroendocrine carcinoma: a case report and review of the literature. World J Oncol 2011; 2: 37-40.

9. Nakanishi C, Sato K, Ito Y, et al. Combined hepatocellular carcinoma and neuroendocrine carcinoma with sarcomatous change of the liver after transarterial chemoembolization. Hepatol Res 2012; 42: 1141-5.

10. Aboelenen A, El-Hawary AK, Megahed N, et al. Right hepatectomy for combined primary neuroendocrine and hepatocellular carcinoma: a case report. Int J Surg Case Rep 2014; 5: 26-9.

11. Nishino H, Hatano E, Seo S, et al. Histological features of mixed neuroendocrine carcinoma and hepatocellular carcinoma in the liver: a case report and literature review. Clin J Gastroenterol 2016; 9: 272-9.

12. Baker E, Jacobs C, Martinie J, Iannitti DA, Vrochides D, Swan RZ. Mixed hepatocellular carcinoma, neuroendocrine carcinoma of the liver. Am Surg 2016; 82: 1121-5.

13. Choi GH, Ann SY, Lee SI, Kim SB, Song IH. Collision tumor of hepatocellular carcinoma and neuroendocrine carcinoma involving the liver: case report and review of the literature. World J Gastroenterol 2016; 22: 9229-34.

14. Liu YJ, Ng KF, Huang SC, Wu RC, Chen TC. Composite hepatocellular carcinoma and small cell carcinoma with early nodal metastasis: a case report. Medicine (Baltimore) 2017; 96: e7868.

15. Doyle MA, Malcolm JC. An unusual case of malignancy-related hypercalcemia. Int J Gen Med 2013; 7: 21-7.

16. Huh UY, Kim JH, Kim BH, et al. The incidence and clinical significance of paraneoplastic syndromes in patients with hepatocellular carcinoma. Korean J Hepatol 2005; 11: 275-83.

17. Burtis WJ, Wu T, Bunch C, et al. Identification of a novel 17,000-dalton 
parathyroid hormone-like adenylate cyclase-stimulating protein from a tumor associated with humoral hypercalcemia of malignancy. J Biol Chem 1987; 262: 7151-6.

18. Abe Y, Makiyama H, Fujita Y, Tachibana Y, Kamada G, Uebayashi $M$. Severe hypercalcemia associated with hepatocellular carcinoma secreting intact parathyroid hormone: a case report. Intern Med 2011; 50: 329-33.

19. Mahoney EJ, Monchik JM, Donatini G, De Lellis R. Life-threatening hypercalcemia from a hepatocellular carcinoma secreting intact parathyroid hormone: localization by sestamibi single-photon emission computed tomographic imaging. Endocr Pract 2006; 12: 302-6.

20. Koyama Y, Ishijima H, Ishibashi A, et al. Intact PTH-producing hepatocellular carcinoma treated by transcatheter arterial embolization. Abdom Imaging 1999; 24: 144-6. 